\title{
Electrochemical Behaviour of Dopamine on A Glassy Carbon Electrode Modified by Graphene Chitosan Copper Composite
}

\author{
S. RENJINI ${ }^{1}$, T. JYOTHISH KUMAR ${ }^{2}$, K. SREEVALSAN ${ }^{2}$ and V. ANITHA KUMARY ${ }^{{ }^{*}}$ \\ 'Department of Chemistry, Sree Narayana College for Women Kollam, Kerala, India. \\ ${ }^{2}$ Department of Chemistry Sree Narayana College Kollam, Kerala, India. \\ Corresponding author E-mail: anithasreevalsan @ gmail.com \\ http://dx.doi.org/10.13005/ojc/330325
}

(Received: December 10, 2016; Accepted: February 02, 2017)

\begin{abstract}
Graphene is a hexagonal honeycombed network of carbon atoms arranged in a single layer which is the fundamental building block of all graphitic materials. The novel properties associated with graphene offer many advantages for electrochemical applications. The present work aims at preparing graphene copper chitosan composite for the voltametric determination of the most prominent catechol amine dopamine. Modified Hummers method was followed for Graphite oxide (GO) preparation. $\mathrm{GO}$ and $\mathrm{CuSO}_{4} \cdot 5 \mathrm{H}_{2} \mathrm{O}$ were brought into an aqueous solution, to this chitosan was added which was refluxed and subsequently reduced to obtain the required graphene-copper composite. The composite was characterized structurally and morphologically by XRD, SEM and it was used for modifying a glassy carbon electrode. The modified electrode was used for sensing dopamine by $\mathrm{CV}$ and DPV. The effect of scan rate and $\mathrm{pH}$ on the performance of modified glassy carbon electrode was evaluated. The fabricated electrode was also evaluated for the simultaneous determination of dopamine and uric acid. This electrochemical sensor was found to be most sensitive and reliable at the physiological $\mathrm{pH} 7$.
\end{abstract}

Keywords: Graphene-Copper composite, electrochemical sensor, Dopamine

\section{INTRODUCTION}

Dopamine (DA) plays an important role in human body as a neurotransmitter in the central nervous system ${ }^{1}$. The biochemistry of DA points to the facts that several diseases such as Schizophrenia, Parkinsonism and Huntington ${ }^{11}$ are caused by abnormal levels of $\mathrm{DA}^{2}$. Levels of
Uric acid (UA) which is the primary metabolic product of human body is in milli molar and micro molar levels in urine and serum respectively ${ }^{3}$. Monitoring the levels of these compounds is has been the target of many researchers. The studies on the electrochemistry of DA are helping us to understand its physiological functions and action mechanism in human body ${ }^{4}$. Different methods 
like capillary electrophoresis, chromatography, fluorometry, chemiluminescence etc. are available for the detection of these molecules. But electro analytical techniques are more acceptable due to low cost, fast response, portable nature and easy fabrication of the sensor for the detection of these electro active species. The most challenging problem in the detection arises mainly due to overlapping of voltammetric signals at many of the solid electrodes and that can be addressed by modifying the working electrode for obtaining well resolved signals. Many modifiers such as polymers, metal oxides and metal complexes have been effectively used together with carbon based materials ${ }^{5-9}$. Graphene a single layer of hexagonal close packed honey comb crystal lattice is being extensively used in various fields such as electronics, optical, magnetic, biological, medicine, energy storage, catalysis etc. Graphene is being widely used in sensor applications due to its exceptional properties such as theoretical specific surface area, high values of Young's modulus, excellent thermal conductivity and amazing intrinsic mobility ${ }^{10}$. Chitosan $(\mathrm{CHI})$ is an aminopolysaccharide. The novel $\mathrm{CHI}$-metal based materials find many applications in the fields of environmental science and technology, catalysis, medicine and

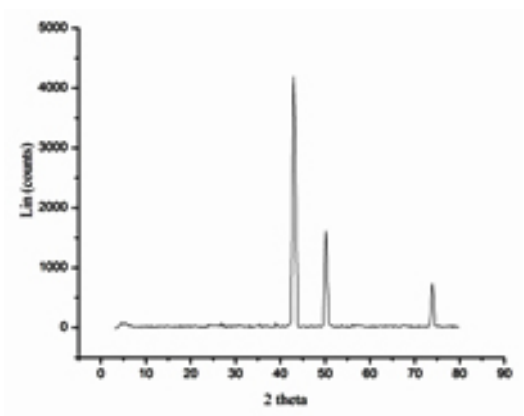

Fig. 1: (A). XRD of GO

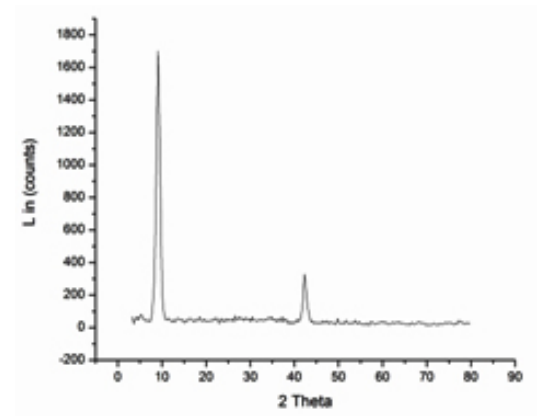

Fig.1: (B). XRD of GN-Cu composite engineering for the development of biosensors. For many years, $\mathrm{Cu}$ and $\mathrm{Cu}$-based electrodes have been used extensively as anodes in electroxidation of organic compounds ${ }^{11-15}$. In the present work we aim at preparing Graphene Chitosan-Copper (GN$\mathrm{Cu}$ ) composite and using it for the voltammetric determination of dopamine (DA).

\section{EXPERIMENTAL}

\section{MATERIALS AND METHODS}

Analytical grade chemicals were used for the present study. Chemicals used for this work were graphite powder, potasium permanganate powder, conc. sulphuric acid, conc. phosphoric acid, $30 \% \mathrm{H}_{2} \mathrm{O}_{2}$, $\mathrm{HCl}, \mathrm{CuSO}_{4} .5 \mathrm{H}_{2} \mathrm{O}$, Acetic acid, Ascorbic acid ,Sodium hydroxide, Hydrazine, Chitosan methanol, etc. All the prepared samples were analyzed by PXRD, SEM. Cyclic voltammetry (CV) and differential pulse voltammograms (DPVs) were recorded using CHI 604D electrochemical analyzer, in a conventional three-electrode cell. A platinum wire served as the counter electrode. The reference electrode was Ag/ $\mathrm{AgCl}$.The glassy carbon electrode (GCE) modified with the composite as working electrode. The study was conducted at room temperature.

\section{Synthesis of graphene - copper composite}

Modified Hummers method was followed for Graphite oxide (GO) preparation ${ }^{16}$. An aqueous solution of $\mathrm{CuSO}_{4} \cdot 5 \mathrm{H}_{2} \mathrm{O}$ and graphite oxide (GO) was made by dissolving in double distilled water. This solution was added drop wise to a solution of chitosan. Reflux with stirring for $20 \mathrm{~min}$. at $120{ }^{\circ} \mathrm{C}$ and added 0.05 $\mathrm{M}$ ascorbic acid. Then 0.6 $\mathrm{M} \mathrm{NaOH}$ solution was added with stirring. Stirr for another 30 minutes and then added $\mathrm{N}_{2} \mathrm{H}_{4}$ and continue stirring for $30 \mathrm{~min}$. more for completion of the reaction and mixture is allowed to cool to room temperature. The solution was centrifuged and washed to obtain pure graphene (GN) Cu-NPs

\section{Fabrication of working electrode}

Alumina slurry was used to polish the bare GCE followed by ultrasonication. The dispersion of the composite in methanol was prepared and sonicated for two hours, and $6 \mu$ l of the composite suspension was drop casted on the surface of GCE and dried in air. 


\section{RESULTS AND DISCUSSION}

\section{Characterization}

Fig $1 \mathrm{~A}$ shows the XRD of $\mathrm{GO}$, the $2 \theta$ peak at $11.7^{\circ}$ corresponds to an interlayer distance of 7.6 $\AA$ A. The XRD of (Fig 1B) GN-Cu nano composite does not have a peak around $10^{\circ}$ indicating

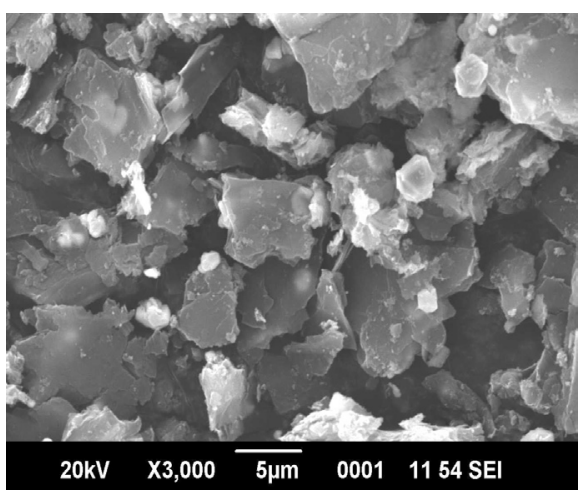

Fig. 2: SEM image of GN-Cu composite

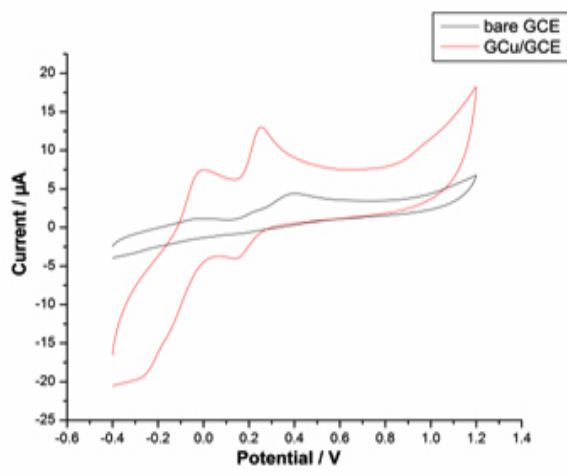

Fig. 3: $\mathrm{C} \mathrm{V}$ recorded at bare GCE and GN-Cu modified GCE at pH 7 in $0.1 \mathrm{M}$ PBS containing DA

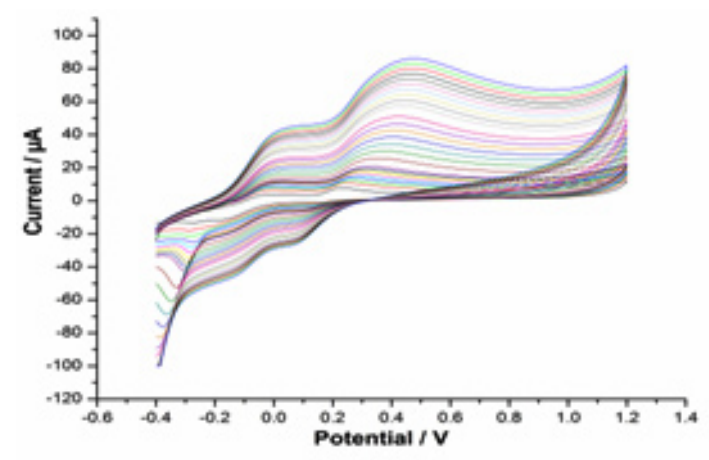

Fig. 5: CVs of 0.2mM DA in 0.1M PBS (pH7) at GN-Cu/GCE, recorded at different scan rates successful reduction of $\mathrm{GO}^{16}$. Composite shows characteristic diffraction peaks at $43.01,50.15$ and 73.8 representing the (111),(200), and (220) crystalline planes of copper respectively ${ }^{17}$. XRD pattern showed that the composites prepared by chemical reduction method posses cubic face centered structure. Purity of the sample is evident

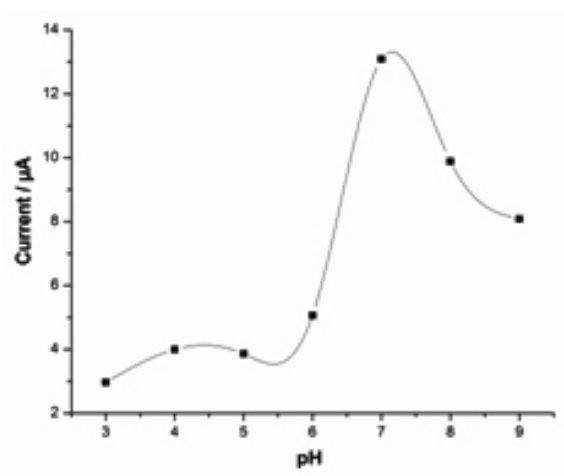

Fig.4 A. Effect of pH on oxidation peak current

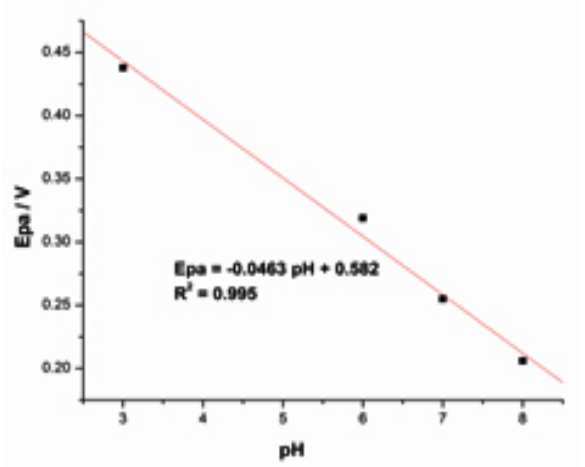

Fig. 4 B. Variation of anodic peak potential with $\mathrm{pH}$

from the absensence of other noticeable peaks in the pattern for $\mathrm{CuO}$ and $\mathrm{Cu}_{2} \mathrm{O}$.. Particle size of as prepared composites by this method was found to be $23.4 \mathrm{~nm}$

The SEM images (Fig 2) also reveals that the $\mathrm{Cu}$ particles are distributed on graphene sheets.

\section{Electrochemical response of DA at modified electrode}

The detection of dopamine (DA) was performed using cyclic voltammetry and differential pulse voltammetric methods. The electro oxidation 
of DA was first examined in bare and modified GCE by cyclic voltammetry in phosphate buffer at $\mathrm{pH} 7$ (fig 3). At the bare GCE an irreversible oxidation peak appeared at $0.404 \mathrm{~V}$. In the modified electrode the peak potential is reduced by $150 \mathrm{mV}$ by appearing a reversible peak at $0.254 \mathrm{~V}$ and peak current is also enhanced compared with the bare electrode. This improvement can be attributed to the edge planes of graphene ${ }^{18}$. The peak at $-0.018 \mathrm{~V}$ is the oxidation peak of copper and it is assigned to $\mathrm{Cu} / \mathrm{Cu}$ (II) transitions $\mathbf{s}^{19,20}$.

\section{Optimization of parameters Influence of $\mathrm{pH}$}

The influence of solution $\mathrm{pH}$ on the electrochemical response was investigated in phosphate buffer solution. The variation of peak current with respect solution $\mathrm{pH}$ in the range 3 to 9 was observed Fig.4A

Results show that solution $\mathrm{pH}$ varies linearly in the range of 3 to 9 with a linear equation of $\mathrm{Ep}=0.58-0.046 \mathrm{pH}, \mathrm{r}=0.995$, (Fig4B). This points to the fact that $D A$ redox reaction is a

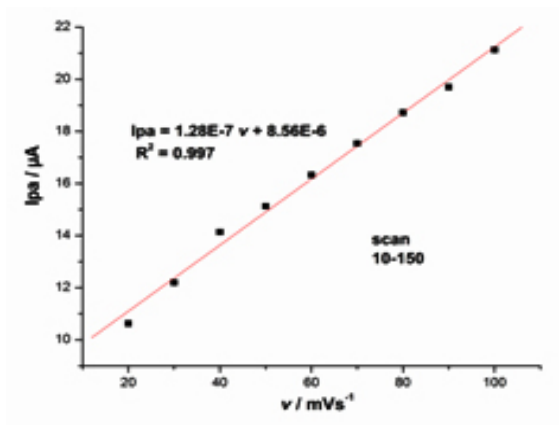

Fig.6A: Variation of oxidation peak current with scan rate (low )

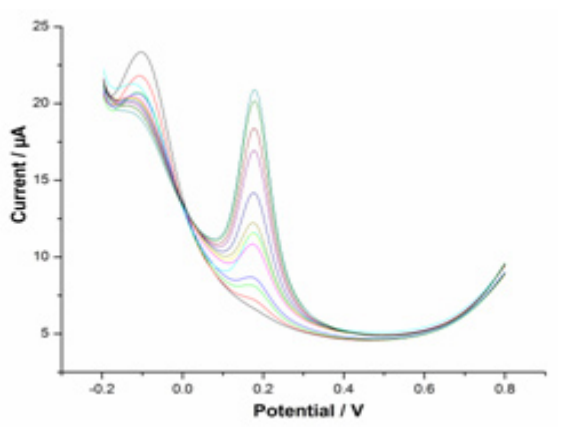

Fig.7: DPVs of different concentration of DA in $0.1 \mathrm{M}$ PBS (pH 7) at GN-Cu/GCE two electron two protons process as already reported ${ }^{21,22}$. Oxidation peak current increases with $\mathrm{pH}$ and reaches a maximum at $\mathrm{pH} 7$, then decreases as the $\mathrm{pH}$ continues to increase. Therefore the $\mathrm{pH}$ at this study is optimized as 7 .

\section{Effect of Scan rate}

Cyclic voltammogram of $\mathrm{DA}$ at $\mathrm{pH} 7$ on GN-Cu/GCE was recorded at different scan rates (v). The scan rate varied as $10-1000 \mathrm{mV} / \mathrm{s}$ are shown in fig.5. There is a linear relation between the oxidation peak currents and scan rate in low scan rate with correlation coefficient of 0.997 for DA (fig.6A), indicating adsorption controlled process. A similar linear relation was also observed between oxidation peak currents and scan rate in the high scan rate up to $1000 \mathrm{mV} / \mathrm{s}$ (fig.6B) with correlations of 0.995 indicating it is also adsorption controlled mass transfer. Hence it is an adsorption controlled process both in low and high scan rate 23,24 .

A linear correlation exists between peak potentials (Ep) and logarithm of scan rates. From the slope of the lines indicate, the number of electron ( $n$ )

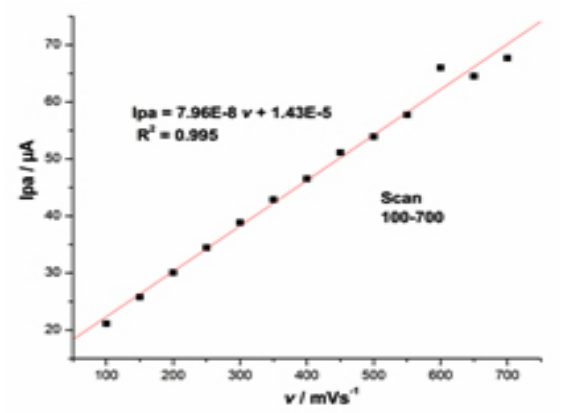

Fig.6B: Variation of oxidation peak current with scan rate ( high )

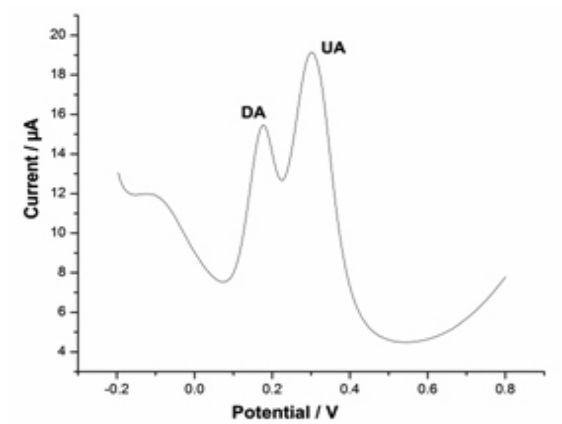

Fig.8: DPV of mixture of $0.1 \mathrm{mM}$ DA and $0.1 \mathrm{mM}$ $\mathrm{UA}$ at $\mathrm{pH} 7$ in $0.1 \mathrm{M}$ PBS at GN-Cu/GCE 
involved in the reaction which is estimated to be two assuming the value of á to be $0.5^{25}$. Therefore the electro oxidation of DA giving electroactive Dopamine quinone $^{26}$ is a two electron two proton process at GN-Cu/GCE. There is appreciable increase in the adsorption and rate of electron transfer at the modified electrode compared to bare $\mathrm{GCE}^{27}$. At pH 7, protonation of the amine group occurs and DA forms

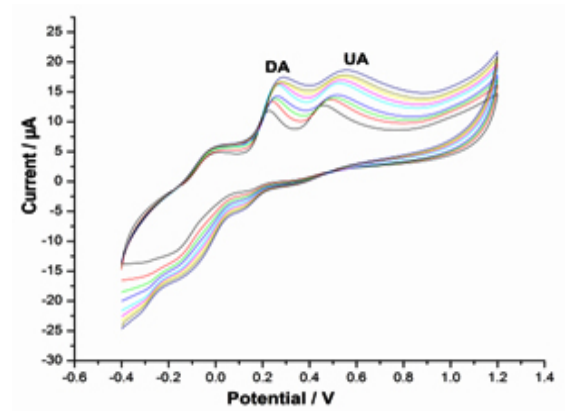

Fig.9: CVs of mixture of $0.1 \mathrm{mM}$ DA and $\mathrm{UA}$ at $\mathrm{pH} 7$ at $\mathrm{GN}-\mathrm{Cu} / \mathrm{GCE}$ recorded at various scan rate.

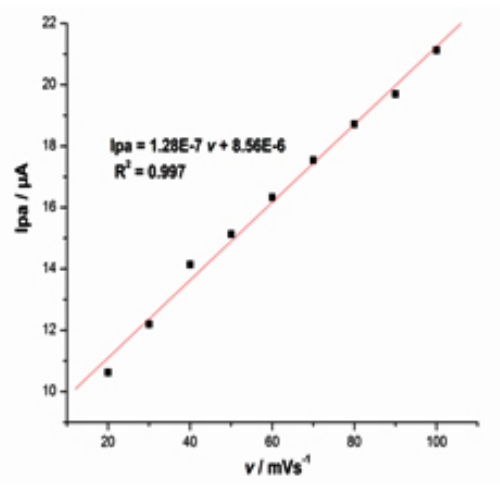

Fig.10A: oxidation peak current Vs scan rate for DA

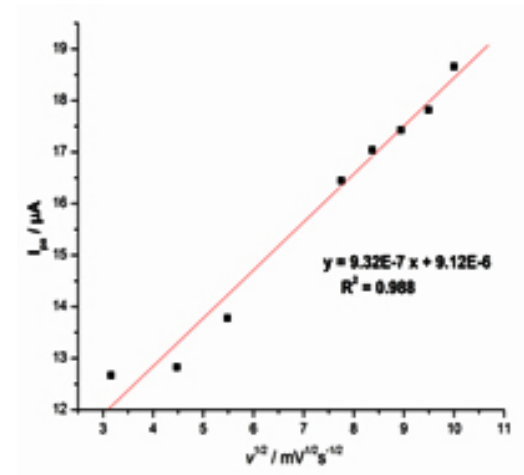

Fig.10B: Variation of oxidation with square root of scan rate for UA an acid conjugate which gets strongly adsorbed on the electrode surface. The phenyl structure of DA and two dimensional planar hexagonal carbon structure of graphene enter into pi-pi interaction making electron transfer highly feasible ${ }^{28}$. The electro oxidation was also accelerated by the copper oxide nanoparticles. Fig.7. represents the DPVs of different concentrations of DA from $0.5 \mu \mathrm{M}$ to $0.1 \mathrm{mM}$ in $0.1 \mathrm{M}$ PBS (pH 7), at GN-Cu/GCE. A linear voltammetric response was obsreved and the detection limits as low as $200 \mathrm{nM}$. The results obtained promise the use of the GN-CuO as an excellent sensor for dopamine.

\section{Simultaneous determination of DA and UA}

Uric acid (UA) is an important interferent as the metabolic end product in the human body ${ }^{29,30}$. Simultaneous determination of DA and UA at GN-Cu modified GCE was investigated using DPV (fig.8). The modified electrode is successful in resolving separate anodic peaks for DA and UA. The GN-Cu/ GCE resolve the voltammetric response of DA and UA into well defined peaks at 0.176 and $0.300 \mathrm{~V}$ respectively indicating that their voltammetric response is independent of each other.

\section{Role of scan rate on simultaneous determination of DA and UA}

The CVs of mixture of $0.1 \mathrm{mM}$ DA and UA in 0.1M PBS ( $\mathrm{pH} \mathrm{7)}$ at GN-Cu/GCE was recorded at different scan rate range from 10 to $100 \mathrm{mV} / \mathrm{s}$ (fig.9). Peak currents exhibited linearly with scan rate indicating oxidation process is surface controlled. Appreciable peak current and separation were obtained at a scan rate of $50 \mathrm{mV} / \mathrm{s}$ and it was optimized for this study. There existed a linear relation between oxidation peak current and scan rate. $A$ correlation of 0.997 (fig.10A) points to adsorption controlled process occurring at the electrode ${ }^{31}$. But for UA a diffusion controlled process is taking place as oxidation peak current varies with square root of scan rate (fig. 10B) ${ }^{32}$.

\section{CONCLUSION}

Glassy carbon electrode modified by graphene copper chitosan composite served as an effective sensor for dopamine at physiological $\mathrm{pH} 7$. Evaluation of the influence of scan rate revealed that it was an adsorption controlled process. 
The redox reaction confirms to a two electron two proton transfer process. The voltametric response was found to be linear for an appreciable range of concentration and reaching a detection limit of $200 \mathrm{nM}$.

\section{REFERENCE}

1. Zhao, H.; Zhang, Y.; Yuan, Z. Analyst. 2001, 126, 358-360

2. Reyes, S.; Fu, Y.; Double, K.L.; Cottam, V.; Thompson, L.H.; Kritik, D.; Paxinos, G.; Watson, C.; Cooper, H.M.; Halliday, G.M.; Neurobiology of Aging. 2013, 34, 873-886

3. Manjunatha, H.; Nagaraju, D.H.; Suresh, G.S.; Venkatesha, T.V.; Electroanalysis. 2009, 21, 2198

4. Zen, J.M.; Chen, P.J.; Analytical Chemistry. 1997, 69, 5087-5093

5. Li, Y.; Lin, X.; Sens. Actuators B. 2006, 115, 134

6. Liu, A.; Honma, I.; Zhou, H.; Biosens. Bioelectron. 2007, 23, 74.

7. Yao, H.; Sun,Y.; Lin, X.; Tang, Y.; Huang, L.; Electrochim. Acta. 2007,52, 6165.

8. Hu, G. Z.; Zhang, D. P.; Wu, W. L.; Yang, Z. S.; Colloids Surf. B.2008, 62, 199.

9. Selvaraju, T.; Ramaraj, R.; Electrochem. Commun. 2003, 5, 667

10. Westervelt, R. M.; Science .2008,320, 324

11. Heli, H.; Jafarian, M.; Mahjani, M.G.; Gobal, F.; Electrochim. Acta. 2004,49, 4999.

12. Torto, N.; Ruzgas, T.; Gorton, L.; Electroanal, J.; Chem. 1999,464, 252.

13. Wu, H.; Cao, W.M.; Li, Y.; Liu, G.; Wen, Y.; Yang, H.F.; Yang, S.P.; Electrochim. Acta. 2010, 55, 3734.

14. Zhao, J.; Wang, F.; Yu, J.; Hu, S.; Talanta. 2006, 70, 449.

15. El-Khatib, K.M.; Abdel Hameed, R.M.; Biosens. Bioelectron .2011,26, 3542.

16. Marcano, D.C.; Kosynkin, D.V.; Berlin, J.M.;Sinitskii, A.;Sun, Z.; Slesarev, A.; Alemany, L. B.; Lu, W.; Tour, J.M.; ACS Nano. 2010, 4, 4806-4814.

17. Eswareiah, V., Aravind ,S. S. J., Ramaprabhu
,S., Mater, J.; Chem. 2011,6800-6803.

18. Mott,D.; Galkowski, J.; Wang, L.Y.; Luo, J.; Zhong, C.J,; Langmuir. 2007,23, 57405745.

19. Abd El-Haleem, S.M.; Ateya, B.G.; Electranal, J.; Chem. 1981, 117, 309.

20. Hassan, H.B.; Abdel Hamid, Z.; Int. J. Electrochem. Sci. 2011,6, 5741-5758.

21. Manjunatha, J G.; Kumara Swamy, B E.; Deraman, M.; Mamtha, G P.; Int. J. Pharm. Sci. 2013, 5, 355-361.

22. T.E. Mary Nancy, V. Anithakumary, B.E. Kumara Swamy, Journal of Electroanalytical Chemistry, 2014, 702-721, 107-114.

23. Peik-See, T.; Pandikumar, A.; Nay-Ming, H.; Hong-Ngee, L.; Sulaiman, Y.; Sensors. 2014, 14, 15227-15243.

24. Fotouhi, L.; Fatollahzadeh, M.; Heravi, M M.,;Int. J. Electrochem. Sci. 2012, 7, 39193928.

25. Hongzhe Kang, Yan Jin, Qian Han, Analytical Letters. 2014, 47, 1552-1563.

26. Farzin, L.; Hosseni, M.R.M.; AJAC. 2011, 2, 289.

27. Banks, C. E.; Compton, R. G.; Analyst. 2006, 131, 15-21.

28. Wang, Y.; Li, Y.; Tang, L.; Li, J.; Electrochem. Commun. 2009 , 11, 889-892.

29. Zen, J.M.; Analyst. 1998 , 123, 1345-1350.

30. Milland, E.; Ordieres, A.J.M.; Blanco, P.T.; Smyth, M.R.; Fagain, C.O.; Talanta. 1996 , 43, 785-796.

31. Mary Nancy, T.E.; Anithakumary, V.; Electrochimica Acta. 2014, 133, 233-240.

32. Ali A.; Ensafi, Taei, M.; Khayamian, T.; Colloids and Surface B: Biointerfaces. 2010, 79, 480487. 